experts in their field, reviewing a narrowly defined topic in the field of infectious diseases. There is no attempt to create an integrated textbook, each chapter stands or falls on its own account, and the reader's interest in the collection will depend on the appeal of the mix of topics contained. The authors are mostly from the USA, and the range of topics covered is wide and prosaic, with reviews of rare or emerging pathogens and infections such as Bartonella species, coccidioidomycosis, and norcardial infections, and more unusual aspects of the host-pathogen relationship in the chapter on Alcohol and infection. There are also welcome chapters on everyday problems encountered in hospitals such as coagulase-negative staphylococcal infections, and the case for once daily gentamicin dosing regimens. I found the chapter on radionucleotide imaging of bone and soft tissue infections interesting, as it covers incoming technology of radiolabelled chemotactic peptides that bind to upregulated white cell receptors at the site of infection. There is also a very useful and thorough review of uncommon gastrointestinal protozoa, some of which (microsporidia and Isospora, in particular) have become more commonly encountered in the AIDS era.

On the whole I find this series stimulating, educating and enjoyable to read, although the information and opinions can only be classed 'current' for a short period of a few months in these fast moving times. My criticisms are minor, and are related to the American orientation of the volume. The chapter on oral cephalosporins demonstrates how different antibiotic usage can be between the USA and the UK, and some antibiotics discussed - such as cefadroxil and lorocarbef - will be unfamiliar, as they are not widely prescribed here in the UK. Likewise the chapter covering the varicella vaccine recommends its use for vaccinating individuals aged $\geqslant 12$ months, which differ fundamentally from current practice and public health policy in the UK and most European countries. The chapter reviewing once daily dosing regimens for aminoglycosides rehearses the many powerful arguments in favour of this practice, but touches only fleetingly on the practical and psychological factors (such as the reluctance of some doctors to countenance flexible dosing times) that seem to block its establishment in many hospitals in the UK.

S. G. JONES

\section{Notes on Medical Virology, 11th edition}

Morag C. TIMBuRY. ISBN 0-443-058458. Churchill Livingstone, Edinburgh. Pp. 196. $£ 12.00$.

Written in a well-structured, concise note form, and containing numerous useful tables and diagrams, this edition, like its predecessors, provides a clear, well-structured, easy to read and learn introduction to medical virology, which is particularly valuable for medical students. This 11 th edition has been extensively re-structured and improved. Chapters have been modified and some even entirely re-written, tables have been updated and new tables have been inserted. Certain deficiencies found in the earlier editions have been rectified, and numerous new additions have been made, including sections on cytokines, lyssaviruses, human herpes virus-8, classification of CJD, automated laboratory technology, HIV viral load assay, new developments in antiviral therapy for a range of viruses (HIV, hepatitis $\mathrm{B}$ and $\mathrm{C}$, respiratory syncytial virus and herpes simplex), and varicella zoster and measles prophylaxis. In addition to the changes in substance, this edition benefits from an enhanced 'new look' presentation, along with improved picture quality.
Although slightly more emphasis on patient management and prevention strategies would have been useful in view of the increasing involvement of medical virology within the clinical setting, this book remains an invaluable, straightforward, simple yet adequately comprehensive and wellillustrated source of knowledge for further generations of medical students, at a very affordable price.

D. MUIR

\section{Molecular Genetics of Bacteria}

L. SNYDER and WENDY CHAMPNESS. 1997. ISBN 1-55581102-7. ASM Press, Washington. Pp. 504. £60.00.

This books attempts to present the fundamentals of bacterial molecular genetics. It was written as a course text for undergraduates or as background reading for those undertaking postgraduate study. While it has many of the attributes of an undergraduate textbook, it is not so basic as to only be of use to the novice. The earliest chapters are on basic molecular biology which could apply to any organism. Subsequent chapters relate to prokaryotes, although there is an inevitable bias towards Escherichia coli. These chapters cover in considerable depth topics such as DNA repair, gene transfer and gene regulation. The last few chapters deal conceptually with some of the techniques of molecular biology and their application.

Although this is a book on molecular genetics, it contains a substantial component of 'classical genetics'. Many of the concepts presented are illustrated by the original experiments that were fundamental to their understanding. As the illustrative experiments chosen were so clearly thought out by their originators, this approach to presenting concepts is extremely successful. It also serves as a reminder of the debt we all owe to the past.

The lay-out of each of the chapters is standardised. The diagrams provided are clear and easily understood. Coloured boxes are used to indicate key points or important examples. At the end of each chapter the authors provide 'questions for thought' and problems. The answers for these are provided. Also at the end of each chapter is a summary box and a list of key references. A glossary and comprehensive index round off the book.

I have a few criticisms. Perhaps some of the technical applications, e.g., PCR, could have had more comprehensive coverage. I also found some of the phage chapters rather heavy going. I would strongly recommend this book to any undergraduate or postgraduate student studying any bacteria in any context. Its price is good value for its contents and hard cover - the latter being necessary to protect this text from the heavy use it deserves.

M. GILL

\section{Infection and Environment}

C. KAPLAN. 1997. ISBN 0-7506-2740-9. Butterworth Heinemann, Oxford. Pp. 151. £16.99.

The potential for this book is vast. The interaction between the environment and infectious disease is well documented and often fascinating. However, although there are some 